\title{
LAS MUJERES INDÍGENAS, MORISCAS Y AFRICANAS: LOS MESTIZAJES Y LA REPRESENTACIÓN DE LA SOCIABILIDAD AMOROSA EN CHILE
}

\author{
INDIGENOUS, MOORISH AND AFRICAN WOMEN: MESTIZAJES \\ AND REPRESENTATION OF A LOVING COEXISTENCE IN CHILE
}

\author{
Maximiliano Salinas Campos ${ }^{1}$
}

\begin{abstract}
El mestizaje ha sido comprendido y enseñado desde una perspectiva colonial y patriarcal a partir de la existencia o el abandono del 'padre' europeo. De este modo, el mestizo es una negatividad histórica, o una reiteración permanente de la violencia del 'padre'. La realidad y la imaginación son mucho más ricas y complejas. En el proceso de la mezcla de las culturas, la participación activa y protagónica de las mujeres no occidentales concedió al proceso interétnico una dinámica más vital y creadora, distante de las representaciones oficiales del Occidente colonial. Las mujeres indígenas, las mujeres moriscas y las mujeres africanas instalaron una forma de vivir donde la experiencia amorosa pasó a ser una experiencia fundante de la convivencia humana.
\end{abstract}

Palabras claves: mujeres no occidentales, mestizaje, sociabilidad amorosa, Chile.

Mestizaje has been understood and taught from a colonial and patriarchal perspective as the existence or the abandonment of a European 'father'. Thus, the mestizo a historical negativity, or a permanent reminder of the violence of 'father'. Whereas its reality and imagination are far richer and more complex. In the process of cultural mixing, the active and leading role of non-western women gave the ethnic dynamic process more vitality and creativity than that presented by official images from the colonial West. Indigenous, Moorish, and African women established a way of life where the sentiment of love became fundamental part of human coexistence. Key words: Non-western women, mestizaje, loving coexistence, Chile.

"Lucila Godoy Alcayaga, [...], era un crisol étnico: española, india, negra, judía y portuguesa" (Vargas 1995:226).

"Esta exaltación de la mujer morena, asociada con la tradición poligámica musulmana, facilitaría y ejercería influjo sobre la hibridización que tuvo lugar en el Nuevo Mundo” (Mörner 1969:26).

\section{Las Mujeres No Occidentales y la 'Mezcla de Razas'}

¿Cómo pensar hoy las formaciones históricas del mestizaje de Chile? La visión del mestizaje en el siglo pasado fue configurada-sobre todo- por los intelectuales masculinos de la elite. Éstos siempre vieron especialmente al roto -el mestizo de Chileen función del orden/desorden de la nación. Y, sobre todo, fue visto el roto: el sujeto masculino; hasta llegar a los pobres 'huachos' -seres desventuradosque describiera Sonia Montecino en su instigante estudio sobre el mestizaje chileno (Montecino 2010. Sobre el arquetipo masculino y violento del mestizaje y sus reiteraciones [León 2005]). El tema del mestizaje en América del Sur ha estado condicionado por el discurso homogeneizador del Estado nación de raíz europea: de la 'patria' o del vacío de la 'patria': la imagen del 'pater ausente'. Nuestra propuesta es poder abordarlo como una experiencia vital que integre y exprese lo ibérico, lo indígena y lo africano en una plataforma de reconocimiento polifónico de la legitimidad de cada uno de estos elementos integrantes e integradores (Wade 2005) ${ }^{1}$.

Habría que comprender a los mestizos, y sobre todo a las mestizas, no tanto como sujetos limitados o defectuosos, sino como sujetos habitados de vitalidad y, por lo mismo -y particularmente-, amorosos. ¿Qué queremos decir con ello? Entendemos como amorosos los comportamientos de las culturas matrízticas como formas vitales de participación, inclusión, colaboración, comprensión, acuerdo, respeto y coinspiración, donde el otro o la otra

$\overline{1}$ Departamento de Historia, Universidad de Santiago de Chile, Santiago, Chile. merquen@gmail.com 
surgen como legítimos otros u otras en convivencia con uno. Implica la dimensión erótica incluida en el conjunto de la experiencia humana (Maturana 2007, 2008). Este amar y convivir amoroso se expresó radicalmente en los fundamentos cruzados de nuestras sociedades mestizas. Desde las tradiciones ibéricas, hispano-orientales, inauguradas en América con el 'safar' (viaje, en árabe) de 1492, las milenarias tradiciones indígenas andinas, $\mathrm{y}$ las sociabilidades africanas que arribaron con el tráfico colonial. Estas últimas no fueron desdeñables: seis mil habitantes de África llegaron aproximadamente a Chile durante la dominación española ${ }^{2}$.

Este fundamento mestizo creó un arte de vivir que tiene pocos símiles en la historia de las civilizaciones. Abrió un horizonte que, sobre todo por su capacidad de vivir y de convivir en las diferencias, originó un espacio amoroso especialmente fecundo en la historia de América del Sur. Nos interesa reconocer la vida amorosa de los mestizos y en especial de las mestizas en la historia de Chile. Fueron en particular las mujeres indígenas, moriscas y africanas -no occidentales- quienes instalaron y promovieron la convivencia humana en Chile desde el mismo siglo XVI. Ellas introdujeron en Chile un estilo de 'vivir' y de convivir, de vivencia y de convivencia, más que un modo de 'morir'? Ellas, como mujeres no occidentales -apartándose aun de las conductas de sus congéneres europeas-, lograron trascender o resistir los comportamientos culturales patriarcales del proyecto colonial castellano, basado en la guerra, la lucha, la competencia y la apropiación de la verdad como formas del vivir en la agresión (Maturana 2007, 2008).

La América del siglo XVI fue, según la expresión de Miguel de Cervantes, "añagaza general de mujeres libres" (Olaechea 1992:39). ¿Quiénes fueron esas mujeres? No tan sólo las mujeres andalusíes o moriscas que se aventuraron tempranamente en los navíos del Atlántico. También las indígenas y las africanas que pese a todas las limitaciones políticas y culturales nunca se eximieron de expresar su amor para alterar la vida -0 , mejor decir, la muerte- de los censores de los sistemas y las fronteras oficiales. La compleja identidad de estas mujeres ni blancas ni occidentales, ni cristianas, al menos en el sentido oficial del término, concedió al imaginario popular chileno -y de América del Sur- una singular sensibilidad amorosa. Contrariando la lógica 'arribista' del sistema colonial en sus múltiples roles de amantes, sirvientas, mancebas, o prostitutas ${ }^{4}$.
El compositor e intérprete de cuecas "chileneras" Hernán Núñez Oyarce expuso ese inquietante mundo femenino de origen colonial tan objetado por sus conductas de "mal vivir" como por ser inequívocamente amoroso:

En la calle del pecado me llamaste a tu ventana de ti se prendió mi vida y mi corazón en llamas.

\section{Carita apasionada} tus ojos moros, ay Rosana, zamba, china, chola, mi negrita, zamba, caramba lindo tesoro.

Lindo tesoro, ay sí, precioso anhelo, ay Rosana, zamba, china, chola, mi negrita, zamba, caramba de mis desvelos.

Aunque una pecadora mi alma te adora, ay Rosana (Núñez 1997:77) ${ }^{5}$.

Esta cueca representa a una mujer distante de los códigos dominantes de la sociabilidad patriarcal colonial de Chile y América del Sur, donde logró expresarse-como la propia cueca o zamacueca- la celebración de una vida y de una femineidad libre de las trabas del estoicismo europeo.

La zamacueca era el baile típico del Perú y especialmente de Lima. Para bailarla bien, había que ser una verdadera limeña, picante y despabilada [...]. Cuentan que un arzobispo viendo bailarla preguntó su nombre: 'La zamacueca, Vuestra Excelencia. -Han elegido muy mal el nombre. Debería llamarse 'la resurrección de la carne'...'. [En] el Perú, como en otros lugares, el baile $-\mathrm{y}$, particularmente la zamacueca- no era siempre inocente [...]. O bien veían en ella una cómoda introducción a la galantería [...]. El ejercicio de la galantería era facilitado por el hecho de que las mujeres del Perú eran más libres que las de España" (Denola 1964:185-186. Sobre el estoicismo colonial, Schmidt 1997:181-204). 
La mulata la Monona, una bailarina de zamacuecas limeñas, dio hacia 1830 especial popularidad a esta danza en Chile. "Desafiando la excomunión -el obispo Manuel Vicuña había declarado a este baile 'cosa de pecado'- la Monona lucía su arte bizarro en el Parral de Gómez [...]. La Monona lucía un estilo garboso y sensual, con picardía y gracia desconocidas". Esta mujer limeña tuvo por discípulas a tres mulatas chilenas, las hermanas Tránsito, Tadea y Carmen Pinilla, "Las Petorquinas" (Garrido 1979:179-180).

Frente a la realidad de esta mujer morena de América del Sur -de plurales rostros y rastros culturales-, sorprendente a los códigos de la normatividad blanca y occidental, las elites europeas intentaron introducir un control estricto sobre la sociedad en general y sobre las mujeres en particular. En términos religiosos, se enfatizó el culto imperial a la Virgen María como emblema ligado al Estado nacional católico (García 1963). En términos políticos, se buscó 'corregir' a las mujeres extraviadas en sus dudosos comportamientos sociales y sexuales (Peña 2000:109132. Sobre el disciplinamiento femenino del siglo XVIII, Vasallo 2006; Araya 2008). La exaltación estatal de la Virgen se representó en la imagen sublime de una mujer en el cielo, y remitió al infierno a las mujeres sospechosas para el imperialismo europeo. Esta mentalidad no fue, por supuesto, aceptada por las mujeres 'de color' (Salinas 1992).

\section{Indígenas, Moriscas, Africanas y las Representaciones de la Sociabilidad Amorosa en Chile}

\begin{abstract}
"Estamos muy lejos de los hermosos tiempos de Atenas y de Roma [...]. El origen más impuro es el nuestro ser [...]. Con tales mezclas físicas, con tales elementos morales, ¿cómo se pueden fundar leyes sobre héroes y principios sobre los hombres?" (Simón Bolívar 1826 en Mörner 1969:90).
\end{abstract}

\section{Las mujeres indígenas}

Los cronistas castellanos y masculinos de Chile observaron con asombro que la principal riqueza, el principal tesoro del pueblo mapuche eran sus mujeres. Pedro de Sosa, guardián del convento de San Francisco en Santiago de Chile - portavoz de la guerra ofensiva contra el pueblo mapuche-, expresó en el siglo XVII:
[Los indios de Chile] no estiman oro, ni plata ni otra riqueza sino es las mujeres. Cásanse con todas las que pueden alcanzar, porque son éstas las que principalmente trabajan y los sustentan en la vida ociosa que apetecen, y son caudal para las borracheras, fragua de adulterio y deshonestidades tales que los hijos no guardan decoro a sus madres, y cometen otros gravísimos pecados en que fundan toda su honra y reputación... (Sosa 1963 [1616]:158-193. Las mujeres como paganización del mundo colonial, Pistone 1992).

La mujer fue el centro de la sociabilidad y la sensualidad de la vida mapuche. El propio lenguaje mapuche, de acuerdo a una sugerencia de José Bengoa, fue especialmente creación y tradición femeninas: "La lengua mapuche no se impuso,[...], por la fuerza de quienes conquistaron, por ser la lengua del Estado. La fue imponiendo la costumbre a través de las mujeres. Un proceso al parecer extremadamente largo" (Bengoa 2007:81). Manuel Manquilef señaló en 1911: "La presencia de una mujer en una fiesta social araucana era la motivadora del amor, porque solo con su mirada cautiva al corazón del enamorado araucano" (Manquilef 1911:20).

Martín Alonqueo, en sus estudios sobre lingüística mapuche, ha dado a conocer la importancia y el sentido de los nombres que el pueblo mapuche concedió a sus mujeres. En cada una de sus expresiones se advierte la profundidad y la finura amorosas para referirse a la personalidad de la mujer. Es una onomástica llena de poesía y de vitalidad en el encuentro con el otro: "Saquin, Shakiñ̃n: Preferida, escogida, alma bondadosa". "Quinturay, Kinturray: la que tiene una flor, la que aspira hallar el néctar y esencia sutil de la flor". "Llanca, Llanka: perla, belleza, generosidad". "Anillang, Anüíllang: mujer decidida y magnánima". "Amuillan, Amuíllang: mujer entusiasta que lleva el altar de su corazón para servir a los demás, magnanimidad". "Sayen, Shayeñ̃n: dulce, amable, cariñosa, mujer de corazón abierto". "Ayínhual, Ayíñwal: huala querida, preferida, amorosa, agradable, generosa". "Ayíqueo, Ayükewün: lenguaje suave, agradable". "Peyeche, Peyeche: mujer inolvidable, recordada, mujer popular, mujer buscada". "Ayínleo, Ayíñleo: amor encendido, amor profundo, lleno de amor, amor inextinguible". "Tripaileo, Trüpaileo: explosión 
de llama, bomba explosiva, mujer explosiva, sensible, ardorosa, impulsiva, ardiente, vehemente" (Alonqueo 1985:21-23).

¿Cómo describieron los españoles o criollos esta atractiva presencia de la mujer indígena? Vicente Carvallo Goyeneche observó una fiesta mapuche del siglo XVIII: "Salen al momento doce mozas igualmente lascivas y deshonestas, también enteramente desnudas, que tomando cada una uno de los ramales, bailan al son de tamboriles; y como al mismo tiempo todos beben, enardecidos con la chicha y el vino, usan torpemente de las mujeres propias y ajenas, a presencia del perverso y obsceno concurso, y dura esta lasciva bacanal hasta que apuran toda la bebida que prepararon" (Carvallo Goyeneche 1796 X:158). Tomás Guevara precisó a comienzos del siglo $\mathrm{XX}$ :

En sus diversiones colectivas, acompañadas siempre de exceso alcohólico, la libertad amorosa se manifestaba tan pronto como el licor, el baile y la mímica lasciva incitaban la imaginación [...]. Estas solteras libres, curre domo, ñua mangere, tenían costumbres extremadamente fáciles. Ejercían la prostitución desde tiempo inmemorial recorriendo los distintos lugares sin obstáculo de nadie (Guevara 1908:41-42).

La importancia de las mujeres mapuches como creadoras de una sociabilidad afectuosa y festiva, incluyendo elementos ibéricos, se apreció claramente en el siglo XVIII. En la zona de Chillán las autoridades españolas procesaron a trece mujeres mapuches por participar en fiestas 'diabólicas' -con música de arpa, guitarra y kultrung-incluyendo la figura de "una viejecita que repartía chicha a todos en un chuico que jamás se acababa" (Casanova 1994).

El jesuita Francisco Javier Wolfwisen en el siglo XVIII expresó detalladamente la convivialidad y el sentido de las mujeres en la sociedad mapuche:

El error que han concebido estos paganos en lo que concierne al cielo los ha endurecido en su deseo de la poligamia. Creen que después de la muerte serán trasladados a un lugar de felicidad situado más allá del mar, donde en medio de una constante abundancia de comida, bebida y de miles de cosas agradables, serán servidos como en esta tierra por muchas mujeres, las que, aunque ya no les procrearán hijos, les darán a beber sin embargo una chicha inagotable. A fin de que no haya mengua de estas deleitables hembras en el más allá, comienzan por procurarse muchas en la tierra, destinadas a servirles de compañía sempiterna (Matthei 1983) ${ }^{6}$.

\section{Las mujeres andalusíes y moriscas}

Esta imagen del cielo -del Paraíso- tiene rasgos acaso islámicos ${ }^{7}$. ¿Contribuyó a ello la población hispano-morisca arribada en los dos siglos anteriores, donde también sobresalieron las mujeres del sur de España? Como adivinara Gabriela Mistral: "[Desde] Cádiz embarcó un mujerío andaluz bastante copioso: Carmen vino a aligerar el remoto país de la piedra..." (Mistral 1994:63). Se asegura que entre 1532 y 1549 llegaron al Perú por lo menos trescientas mujeres calificadas de moriscas. Ellas transmitieron su cultura dejando un legado árabe visible en numerosos aspectos, como la vestimenta al estilo musulmán, las comidas, y la propagación de tonadas y danzas del Oriente (Cáceres Enríquez 1995).

En particular, las mujeres andalusíes del siglo XVI alcanzaron un inmenso prestigio por sus costumbres amorosas en todo el Mediterráneo. Expresaron un modo de vida donde se podía disfrutar libremente de la dimensión sexual y erótica. La Lozana andaluza, la obra de Francisco Delicado de 1524 acerca de una cortesana de Córdoba del siglo XVI, muestra bien este espíritu rebelde y amoroso del 'mujerío andaluz' (Fourquet-Reed 2004). Las mujeres moriscas fueron mal vistas por la cultura católica europea por su desenvoltura corporal. Se las criticó hasta por el carácter ligero de sus vestimentas ${ }^{8}$.

La sociabilidad oriental implicaba el cultivo del placer como ritual sagrado o 'majliss', donde la presencia de las mujeres era protagónica. Éstas, mezclando los atractivos sexuales con los talentos artísticos y poéticos, contribuyeron a darle una nota característica a la vida social y a la intimidad cotidiana: "La sensualidad del 'majliss' aumentaba gracias al vino y a la compañía de mujeres" (Mernissi 2006:151-166). En contraposición con el espacio público, territorio de la guerra, en Oriente el territorio de la paz se cultivó en el espacio interior del 'harén', donde las mujeres sobresalieron por su erotismo y su encanto, y donde los hombres se convertían en vulnerables: "Cuando amamos dejamos caer las murallas, borramos las fronteras y eliminamos las barreras. Entonces ya no nos afectan los límites" (Mernissi 2003:72). 
De la mayoría de mujeres españolas solteras que pasaron a Indias a principios del siglo XVI -señalan Eduardo Cavieres y René Salinas- "un número apreciable lo constituyeron prostitutas y cortesanas,... [En] Potosí hacia el año 1582 se contabilizaron 120 mujeres españolas de oficio licencioso" (Cavieres y Salinas 1991:26). Estas mujeres pudieron fácilmente pasar a Chile, y con probabilidad fueron parte de las "cautivas y forzadas españolas" que originaron la "multitud de mestizos" presentes en el territorio mapuche a principios del siglo XVII (Sosa 1963 [1616]:161). Se estimaron quinientas españolas en territorio indígena de Chile (Esteva Fábregat 1988:160, ver también Ginobili 1996). Estas mujeres del Mediterráneo participaron mucho más que en otros lugares de América en la mezcla de razas y convirtieron la tierra mapuche en un lugar donde se podía amar y ser amado. Fueron las mujeres que "bramaban" -como recordó Gilberto Triviños- por querer vivir entre los indígenas de Chile (Triviños 1994:110).

Es probable que estas mujeres de cultura y espíritu oriental transmitieran no poco de la vida afectiva propia del mundo árabe, esa ternura, o 'rahma' que proporcionó una identidad distinta a la de la agresión colonial: "Rahma es un concepto rico y polifacético, es a la vez la sensibilidad (' $a r$ riqa'), la ternura ('at-ta'attuf') y, también, el perdón ('al-magfira'). Todo lo que es dulce y tierno, que alimenta y da seguridad como un útero (' $\mathrm{rahm}$ ') viene de la misma raíz. La lluvia es rahma porque aporta la prosperidad ('al-jayr')" (Mernissi 2007:159). No se debe olvidar que el mundo femenino en la España del siglo XV -no ajeno a la gran tradición oriental-fomentó un espíritu libertario y amoroso que llama hasta hoy la atención de los especialistas (Rodríguez-Puértolas 1992; Rudelle-Berteaud 2002).

La proverbial sensibilidad amorosa de las mujeres andalusíes se expresó en la poesía escrita durante siglos por ellas mismas: "Dulce morenito. / ¿Qué suerte la del amante / que duerma contigo!", "Boquita de perlas en collar, / dulce como la miel, / ven, bésame, amigo, / ven junto a mí..." (Rubiera Mata 1990:45).

\section{Las mujeres africanas}

"A la zamba refalosa y en ella refala mi alma. No llores, Negra, que tuyo soy" (Aretz 1978:559).
"Ay negra, ay samba, ¿quién será tu dueño?, más tarde ¿cuándo yo me vaya?, mañana" (Limonchi 2007:179).

Escasamente reconocidas en la sociedad colonial chilena y sudamericana las mujeres africanas tuvieron una notable presencia desde el siglo XVI. La historia de las mujeres afrodescendientes en Chile ha comenzado a reconocerse cada vez más (Flusche y Korth 1983; González 2008; Soto 1992;). La mujer en África fue un importante símbolo de la vitalidad y de la fecundidad del mundo. Esto es evidente en sus manifestaciones artísticas, religiosas y culturales.

La maternidad es una representación habitual en la iconografía africana, usualmente ligada a la fecundidad y con representaciones a veces tan potentes como sensuales y conmovedoras. En algunas sociedades matrilineales es ésta la imagen de la primogénita mítica, también de todas las mujeres, por la que se transmiten los derechos de sucesión [...]. Las maternidades kongo reproducen la figura de una mujer con su hijo en diferentes actitudes y están ligadas al poder espiritual y a la fecundidad, y destinadas a poner fin a la mortalidad infantil y a la esterilidad [...]. Al igual que las figuras de los antepasados, las maternidades son una representación espiritualizada de la supervivencia (Lentini 2004:52).

Las mujeres afrodescendientes en América del Sur mostraron un sentido de la vida que no se dejó determinar absolutamente por la dominación esclavizante de los europeos. Las mulatas fueron, en muchos casos, para los demás y para sí mismas, la representación de un sentido erótico de la realidad ${ }^{9}$.

Las mujeres mulatas y zambas en el Perú colonial albergaron una experiencia amorosa o erótica sospechosa para el frágil orden europeo. Como ha expuesto María Emma Mannarelli, podían tener encuentros sexuales con el diablo, o invocar al sol y a la luna, al Inca y a la Colla para los éxitos amorosos. Incluso podían recurrir para ello a la imaginería cristiana.

Juana de Apolonia, zamba esclava, mientras se valía de los conjuros al diablo, usaba 
'varios ungüentos para los dichos ungüentos amatorios diciendo traía a los amigos a la ilícita amistad de las mujeres por medio de la Virgen María y de los santos (Mannarelli 1998:33-35).

Vinculadas, pues, a las prácticas hechiceriles, las mujeres afrodescendientes, muchas veces acusadas de llevar una vida escandalosa y de mantener amistades ilícitas, dieron espacio a "una sexualidad femenina que se resistía a ser reprimida por las normas impuestas por las elites" (Mannarelli 1998:41).

Las mujeres afrodescendientes sobresalieron por una sensibilidad a flor de piel que sorprendió a cualquiera que las conociese, aunque fuese ocasionalmente. Un viajero inglés de paso por Mendoza, Argentina, recordó a principios del siglo XIX:

[Nos] despedimos de la fonda mendocina. La última persona a quien dije adiós fue la vieja negra cocinera que realmente lloraba al vernos partir. Era una de las criaturas más afectivas y fieles que haya conocido. Se me acercó al momento de partir para pedirme que me cuidase, entre llorando y riendo (Head 1920:94).

La religión africana promovió desde sus propias experiencias simbólicas la imagen extraordinaria de una mujer amante y dulce en la representación yoruba de Oshun, diosa nigeriana del amor (Zaramaira 2007).

\section{Interidentidades Mestizas}

Aunque soy morenita

no me trocara

por otra que tuviera

blanca la cara.

Blanca la cara, sí,

blanca azucena

si la azucena es blanca

yo soy morena.

Azúcar y canela

son las morenas (Acevedo Hernández

1953:255).

La población de Chile en el siglo XVIII integró un mosaico demográfico donde lograban reconocerse rasgos indígenas y moriscos, aparte de los africanos, fundidos en un multiplicado mestizaje. De acuerdo a un documento jesuita de 1724, la población de Chile contaba, además de europeos y criollos, "mestizos o cholas de españoles y de indios", "mulatos de españoles y negros" y "chambos, semiindios y semimoros" (Mühn 1946:45). Este conjunto multiforme implicó una sensibilidad amorosa singular. La particular herencia de la mujer indígena en la vida íntima de los mestizos y las mestizas en Chile se advirtió hasta en la misma designación popular del acto sexual (la designación del acto amoroso proviene del aymara "ccaccha", o "kakcha", "pecado nefando entre mujer y mujer", Lenz 1905-1910:151).

Con toda seguridad, estas sensibilidades y prácticas amorosas desconcertaron a la cultura burguesa que comenzó a influir en la región en el siglo XVIII y a principios del siglo XIX. Amadeo Frézier señaló de las mujeres limeñas:

Tienen los ojos vivos, la charla placentera, gustando de la galantería libre, a la que responden con ingenio y a menudo con giros que huelen algo a libertinaje según nuestras costumbres. Las proposiciones que un amante no se atrevería hacer en Francia, sin merecer la indignación de la mujer honrada, lejos de escandalizarlas, las complacen, [...]; las agradecen como si les hiciera un honor, en lugar de enfadarse como si tuviesen mala opinión de su virtud (Descola 1964:186).

Los científicos Juan y Ulloa opinaron de este modo:

[Estas] mestizas y mulatas desde el segundo grado hasta el cuarto o quinto se dan generalmente a una vida licenciosa, aunque entre ellas no es reputada por tal, mediante que miran con indiferencia el estado de casarse con sujeto de su igual o el de amancebarse (Descola 1964:187).

El cronista franciscano del Perú en el siglo XVIII Eugenio Lanuza refiere esta viva instantánea:

Habiendo encontrado en la sala donde nos hospedamos a una moza aprisionada en un cepo, le preguntamos la causa de aquella pena, a que respondió que porque un mozo 
había tenido un retozo con ella, de cuya jocosidad le había resultado una inflamación en el vientre, [...]. Reímos de la lisura de la moza y partimos de la mesa un bocado con ella,..." (Lanuza y Sotelo 1998:73).

Un viajero en Argentina comentó de las mujeres del pueblo hacia 1825: "[Todas] tienen familia aunque no sean casadas; y una vez que pregunté a una joven ocupada en amamantar a una lindísima criatura, quién era el padre, contestó: ¿quién sabe?” (Head 1920:33).

Hacia 1818 el norteamericano John Coffin identificó en estos términos a las mujeres chilenas de la zona de Concepción:

[No] tienen nada de esa reserva en la conversación o en el porte que siempre he creído instintiva del carácter femenino [...] pasan por ser ardientes, fieles y afectuosas, pero en cuanto a los sonrojos de la modestia, es cosa que no sospechan [...]. Tienen aun las más serias cierto aire desconocido y sin pudor y en sus relaciones con el otro sexo admiten libertades y familiaridades en la conversación que entre nosotros se considerarían indecentes. No existe aquí nada de reserva y tímida emoción que se experimenta en presencia de la mujer amada que constituye el encanto de la sociedad culta en los tiempos modernos (Cerda 1989:157-171).

Samuel Arnold anotó en su viaje por América del Sur a mediados del siglo XIX:

Aquí tienen ideas raras sobre moral. Mr. H. dice que hay madres que le han traído sus hijas para que fueran sus amantes, [...] el concubinato se toma muy a la ligera en este país y en toda la América del Sur española (Arnold 1951:169).

Enrique Molina llegó a decir en 1917: “[La] institución matrimonial tiene menos fuerza en la costa occidental de la América del Sur que en cualquier país cristiano, que en los pueblos musulmanes, o en las sociedades de la India, de la China y del Japón" (Molina 1917:42-44).

Desde los orígenes de la sociedad colonial en Chile la presencia de las mujeres indígenas y africanas fue, sobre todo en el perturbador $-¿^{\mathrm{O}}$ liberador?- espacio nocturno, motivo de inquietud política y cultural. Oscuridad de la piel, oscuridad de la noche. En 1551 el cabildo de Santiago prohibió el deambular de estas mujeres bajo la amenaza de cien azotes (Cavieres y Salinas 1991:33). Otro tanto lo fueron las mujeres 'lusitanas' - ¿portuguesas?quienes en las noches del siglo XVII escandalizaron a las autoridades de la Iglesia santiaguina. El sínodo diocesano de 1688 denunció:
la disolución de muchas Mujeres Lusitanas, que en comenzando a cerrar la noche, salen de sus Casas, y se van a las Tiendas [...], y de otros Oficios, con pretexto de comprar los Géneros que necesitan; gastando lo más de la noche, así en las Tiendas como en la Plaza y Calles, en disoluciones, y graves ofensas de Nuestro Señor, de que lo religioso y serio del Pueblo está escandalizado; [...]. (Sínodos 1983:64-65).

¿Qué peligro constituyeron para el orden y la pureza de los blancos? Es probable que la sola presencia de las mujeres en los espacios públicos fuera para los blancos un problema.

En una sociedad como la colonial, la sola
presencia de las mujeres en los espacios
públicos tenía implicancias deshonrosas. Su
vulnerabilidad en lugares como las cortes
estuvo fuertemente asociada a la exposición
de su vida sexual (Mannarelli 1998:17).

La vida y las costumbres de las mujeres del pueblo atrajeron la atención de los observadores extranjeros durante los siglos XIX y XX. Al desembarcar en Valparaíso en 1830 el naturalista francés Alcides D'Orbigny reparó en la conducta de las mujeres mestizas:

Allí, por la tarde, se ve, a la puerta de cada casa, señoritas hermosas y bien vestidas, que son las primeras en pedir que uno entre cuando se les dirige la palabra; tratan luego de distraer a sus visitantes cantando, acompañadas por guitarras. Uno se asombra mucho al hallarse de improviso como en casa de conocidos; pero, algún tiempo después de vivir en la ciudad, aunque encontrando en todas partes la misma hospitalidad, no 
se tarda en descubrir que no es allí donde debe buscarse la buena sociedad del país. Ese gran número de mujeres jóvenes, que puede contemplarse cómodamente al pasar, me sirvieron para juzgar, si no el conjunto (porque las mujeres de alta sociedad tienen rasgos más distinguidos), por lo menos una clase entera de la nación. Comprobé una gran diferencia en la forma del rostro, comparadas con las mujeres de Buenos Aires: en Chile, la cara es generalmente redonda y participa, sin duda, algo de los rasgos de los araucanos, [...] (D'Orbigny 1958:529-530).

Fue el clima propio de una época en la cual los suburbios urbanos mostraron -como ha apuntado Gabriel Salazar- a las "mujeres sonrientes, independientes, desinhibidas, que 'sabían' ofrecer alimentos, tejidos, bebidas y hospitalidad [...]. Así, dondequiera que se instalaban, producían vida, movimiento, comida, bebida, canto, baile, sociabilidad desenfrenada" (Salazar 1992:99).

El parecer de los extranjeros al respecto se volvió intransigente con el siglo XX. En 1925 se implantó en Chile un código sanitario, el Código Long -en reconocimiento al médico higienista norteamericano John Long- que prohibió "el ejercicio de la prostitución y de cualquier práctica que conduzca a la exposición de una mujer a todo género de torpeza y sensualidad" (Góngora 1994:233). En 1954 Benjamín Subercaseaux, con su mirada inquietante frente a la cultura popular, se perturbó ante la "consigna diabólica de sensualidad que caracteriza a nuestro mestizo" (Subercaseaux 1954).

Las mujeres mestizas o morenas de Chile, con sus ancestros indígenas, africanos y moriscos, no 'comprendieron' -al modo de la racionalidad occidental y burguesa- el mundo que las rodeaba. Lo 'palparon' desde su modo de ser afectivo. Celebrando a Gabriela Mistral, escribió el filósofo mexicano José Vasconcelos:

Su raza nueva -araucana y española se proclamaba ella- nos da un mensaje rico en densidades de madurez; trémulo de inquietudes que abarcan todos los temas, lúcido y siempre franco, atrevido. Poetisa de la tierra, su expresión es siempre concreta, su visión a veces nos desconcierta, por cierta insistencia en la carnalidad, como cuando compara las desgarraduras de la serranía con vértebras y músculos al descubierto. ¿Hay un tipo de pensar que al mismo espíritu quisiera hacer carne, y lo exprese en imágenes y símiles que lo vuelven cosa de palpación más que de comprensión? (Vasconcelos 1946:224).

El asombro del filósofo mexicano nos aclara el deslumbramiento provocado por el ser mestizo de Gabriela Mistral, capaz de superar la propia retórica intelectual del pensador de la 'raza cósmica'.

La sensualidad de la mujer morena -iindígena, morisca, portuguesa, africana?- en el imaginario mestizo de Chile ha quedado representada, entre otras manifestaciones, por la poesía popular de Roberto Parra en la figura literaria de la Negra Ester ${ }^{10}$. Sus formas de expresividad popular fueron -por supuestoimpugnadas de plano y sobre todo por las mujeres autoproclamadas blancas, europeas, renuentes de modo real o simbólico a la representación mestiza. Según Joaquín Edwards Bello:

Estas damas, descendientes de conquistadores y de funcionarios coloniales, sin mezcla con nativos, pugnan por retornar a la naturaleza europea de los bisabuelos y chocan con el clima adverso. Por eso viven en eterna batalla y el pueblo moreno asume para ellas la encarnación de una amenaza secular [...]. Las mujeres ricas, de raza blanca, creen descubrir en sus criadas morenas las más sutiles y constantes e invencibles enemigas de su propiedad, por cuanto las pobres conocen los secretos de la tierra (Edwards Bello 1955:84, 346).

Estas mujeres morenas fueron quienes cultivaron la interpretación de los cancioneros amorosos populares, como bien comprobó el filólogo alemán Rodolfo Lenz (Salinas 2011).

¿Desciende el pueblo chileno, en más de algún sentido, de estas mujeres morenas de los siglos XVI, XVII y XVIII? Ellas fueron -o preciaron serlolibres, desenfadadas. En cierto modo, escandalosas. Fueron las cantoras y danzarinas de las atrevidas 'zamacuecas' y 'mozamalas'. La 'mozamala' puede aludir a las mujeres "malas de sus cuerpos", esto es, renuentes al canon moral de Occidente. La diosa andina de la coca, la 'Mamacoca', era una mujer hermosa y que por ser "mala de su cuerpo" 
fue asesinada. Pero de su cuerpo nacería el árbol de la coca (Bendezú 2003:48-49. La 'mozamala' y la 'zamacueca' fueron bailes, probablemente, de herencia mora y sahariana, cfr. Delgado 2000:92).

A principios del siglo XIX, durante la guerra de la Independencia de Chile, refirieron las autoridades, había que "mantener en reclusión y virtuoso entretenimiento a tantas mujeres cuyo desenfreno ha llegado a lo sumo". "Esas mujeres que son la piedra del escándalo y el origen de unos perjuicios que refluyen contra la conservación del orden y arreglo de costumbres" (Peña 2000). Ellas fueron las adversarias peligrosas del orden realista o patriota del momento. Había allí una libertad tal que no le convino a ningún representante de la sociedad aristocrática -monárquica o republicana- de Santiago. Menos al régimen todavía simbólicamente monárquico de mediados del siglo XIX. El reglamento de la Casa de Corrección de Mujeres de 1853 criminalizó a las mujeres pendencieras, vagas, escandalosas, que huían del lado de sus madres, por no contenerse a su marido, por lenocinio, por amancebadas, por amistad ilícita, por adúlteras, y un largo etcétera (Peña 2000). En el siglo XIX operaba todavía el principio político monárquico virginal de la pureza colonial (Araya 2004). Las mujeres mestizas en los Andes fueron tachadas de "inmorales" hasta el siglo XX: operaba la imagen de la "mestiza grosera e inmunda" (De la Cueva 2004).

Es probable que de esas mujeres morenas aprendiera el pueblo chileno el carácter fluido y espontáneo de su comunicabilidad amorosa. No necesariamente relacionado ni identificado con el padre blanco -situación que condenaría al mestizo a la repetición de la violencia colonial original-, creemos que el pueblo chileno se sintió heredero, hijo de estas mujeres morenas ${ }^{11}$. Esta filiación podemos hallarla de modo espléndido en el elogio de Violeta Parra realizado por su hermano Nicanor (Defensa de Violeta Parra).

Particularmente, el pueblo se sintió heredero de las 'chinas', como se identificó a las mujeres plebeyas, denominándolas con esta expresión quechua. 'China', si bien tuvo un carácter de discriminación racista -por parte de las elites-, en su expresión 'chinita' fue una fórmula sobresaliente de afecto y de cariño. "La palabra 'china' [...] pasó de la lengua kitshua al español vulgar, de la que se deriva la forma afectuosa "chinita"" (LehmannNitsche 1981:284).
Las 'chinas' fueron calificadas como indígenas sospechosas de romper la decencia del orden católico establecido ${ }^{12}$. Por su parte, las 'chinas' animaron la vida festiva y amorosa chilena del siglo XVII: "[La] Dominga Flores y sus tres 'chinas' lanzaban al aire sus potentes y experimentadas voces al compás de un esquinazo con arpa y guitarra. La Dominga era la mejor 'cantora' de Santiago [...], ella y sus hijas animaban cualquier fiesta cantando tonadas y 'sajurias' durante toda la noche" (C. Salinas 1994:107).

Las 'chinas' estuvieron relacionadas en las sociedades indígenas de los Andes con el mundo de las concubinas.

Las concubinas recibían el apelativo de 'chinakuna'. Si 'warmi' significa mujer y se reservaba para las esposas legítimas, 'china' significa hembra y se reservaba para las concubinas [...]. De manera que el vocablo 'china', sensu stricto significa hembra. Aplicado a las mujeres se utilizaba para las concubinas, que eran 'hembras' de sus maridos y no esposas (Ellefsen 1989:48).

Las 'mamakunas' que ejercían como concubinas recibían el apelativo de 'intip chinan' o 'punchao chinan', esto es, criadas del sol o siervas de la luz del día, pero nunca el de mujeres del sol. El término 'willka china', literalmente, 'hembra sagrada', designaba una jeringa para enema usada en la cópula sexual con características afrodisíacas y alucinógenas (Ellefsen 1989:173, 314).

\section{Un ritual mestizo de raíz femenina: la 'china' de Andacollo y la convivencia amorosa en Chile}

“Todos los que están allí, vistos a la luz de las estrellas, son gente morena, como nosotros, y debió serlo hasta el recién nacido, a pesar de los cromos del cristianismo a la inglesa, y tostado sería después, de vivir al sol de los campos y caminar en pespunteo de aldea en aldea.

(Un poco más allá de Palestina, vive el romano blanco, y 'sabido', y dueño del mundo. Pero el recién nacido asomaría en la Judea colonial, y mínima, y paupérrima) $[\ldots]$. 
No es mera estampa de yeso ni tarjeta de Noel lo del niño que duerme a la escarcha y a la ventisca. A lo largo del Pacífico, del Atlántico y del Caribe, yo me he visto entredormir de ese modo al chiquito indio, al mulato, al negro y al mestizo" (Mistral 1949).

Uno de los acontecimientos más notorios de la sociabilidad amorosa de Chile colonial nació en el Norte Chico cuando un indígena diaguita -resistente al sistema colonial: los indígenas destruyeron la ciudad de La Serena en 1549- se "encuentra" hacia 1560 o 1570 con la imagen de una mujer en principio española pero que es convertida o transfigurada en 'china'. Es la 'china' de Andacollo. La imagen de la Virgen María - principio de inviolabilidad y pureza del régimen regio de la Casa de Austria- se trasmuta en una mujer morena a la que se la debe reconocer con cantos y bailes propios de las ritualidades andinas. ¿Fue ella expresión de los cultos a las diosas andinas? "La voz Andacollo deriva del quechua Anta-Coya, que significa cobre-reina" (Uribe Echevarría 1974:45).

En la montaña un poco mágica de Andacollo, el oro va por arroyos y regatos, en pepitas de mostaza o de arroz. Estas aguas milagrosas, que nacen al pie de un templo indígena, mantenían antes a grupos de naturales que no querían violentarlas por no extinguirlas; [...] (Mistral 1978:190).

Es casi seguro que se celebrara allí un culto a las divinidades telúricas tutelares a las que se les concedieron capacidades reproductoras y protectoras. "En las minas, que ellos dicen 'coya', reverenciaban a los metales mejores, que llaman 'mama', y a las piedras de ellos las horadaban, besándolas, con diferentes ceremonias..." (De Murúa 1616 en Hernández 2002:28).

Este 'mochar' (beso sagrado) a las piedras se realiza porque se les atribuye una capacidad reproductora y protectora. Además, al asociarlas al género femenino y el denominar a las piedras que representan los minerales 'mamas' indican su capacidad de reproducción y protección (Hernández 2002:28).
En términos ibéricos y mediterráneos, a lo mejor esta imagen femenina tampoco sería del todo cristiana. ¿Acaso fue morisca? Mora, morena, reconocida como mujer divina por los moros en España. María fue admitida por los musulmanes de Al Ándalus como una mujer corporalmente generosa, capaz de brindar el alimento de sus senos: la leche materna. En el siglo XIII las Cantigas de Santa María -recolección medieval de leyendas y tradiciones orales- señalan a esta mujer viva y amorosa. La Cantiga 46 revela "cómo la imagen de Santa María echó leche de las tetas ante el moro". "Quand' a imagen enton / viu duas tetas a par, / de viva carn'e d' al non, / que foron logo maar / e deitar / leite como per canudos" (Salvador 2006:329-330).

La 'china' de Andacollo -entonces mezcla de zamba, china, chola- estructuró la cultura y el lenguaje popular de Chile con una inclinación amorosa específica. Sabemos también que la 'china' es la 'niñera, aya de los niños', y 'chinear' puede significar 'llevar en brazos'. Es la madre, o la que hace de madre (Bayo 1910:78). Pero también es la mujer amante, amadora. La palabra 'china' se encuentra en los refranes amorosos y festivos de América del Sur: "China sin amor es más rara que comesario güen perdedor" "Ñatita y retacona, chinita alegrona" (Moya 1944:383, 565). En el Perú se dice: "Era china zalamera / muy guapa y muy oscurita; / era en todo muy bonita / fresca como un mes de abril. / Sólo le pude decir / Mamita, mi señorita..." (Santa Cruz 1982:309). En Argentina, el gaucho a su mujer amada la llama 'china'. En Chile Rodolfo Lenz la definió también como "querida, manceba, mujer pública” (Garrido 1979:100).

El lugar de culto de la 'china' de Andacollo, en el siglo XVII, fue, en el decir de las autoridades coloniales de la época, sólo una "ramada indecente", y su festividad a principios del siglo XIX se extendía por quince días (Mellet 1959). La 'chinita' pasó a ser celebrada durante la fiesta de Navidad, en el solsticio de verano, como alumbramiento de un sentido histórico habitado por la solidaridad y la comunidad del nuevo pueblo mestizo, y no por el principio de la 'seriedad de la muerte' impuesta por los Habsburgo. La imagen sagrada se sitúa en el terreno del principio del placer, donde el pueblo se une con un mundo restallante de vida. Ella es origen de la vida y del eros que permite alterar el sentido de la historia en favor de los pueblos. A diferencia del padre blanco quien -como un dios masculino e indiferente-mantiene inconmovibles las estructuras 
de la dominación. Esto lo expresó un baile del valle de Elqui a mediados del siglo XX: "Y Dios con su omnipotencia / y su corazón tan noble / al rico lo tiene rico / y al pobre lo tiene pobre" (Baile San Isidro de Elqui ${ }^{\circ} 10$ en Uribe Echevarría 1974).

La 'china' de Andacollo refleja la relevancia y la vigencia de la cosmovisión andina donde la figura paterna está prácticamente ausente del universo mítico. La relevancia reside en el binomio madre-hijo (Hernández 2002, según Rostworowski 1983). También puede relacionarse con la importancia de las mujeres andinas que fundan la armonía del orden social y cósmico. Como una de las míticas coyas, la Cusi Chimbo Mama Micay Coya, de quien dijera Guamán Puma de Ayala, era "amiga de cantar y música y tocar tambor, hacer fiestas y banquetes y tener ramilletes en las manos" (Hernández 2002:125).

En su condición de mujer morena, la 'chinita' de Andacollo apela también a una estética andina del amor. Es la mujer particularmente amada y amable. Un canto quechua, un 'arawi', reproducido por Guamán Puma de Ayala, dice así:

Morena mía / morena / tierno manjar, / sonrisa del agua, / tu corazón no sabe / de penas / y no saben de lágrimas / tus ojos. / Porque eres la mujer más bella, /.../, dejo que el agua del amor / me arrastre en su corriente, / dejo que la tormenta / de la pasión me empuje / allí donde he de ver la manta / que ciñe tus hombros / y la saya resuelta / que a tus muslos se abraza (Bendezú 2003:20).

Esta morenidad se relaciona notablemente con la estética mediterránea de la mujer morena. En Andalucía la imagen sagrada de María fue celebrada como morena. Lope de Vega conoció una devoción sevillana: "Que del cielo tienes / morena graciosa / en el pecho las puertas / en la boca las llaves" (Portocarrero 2007:98). La Virgen del Carmen de los gitanos es también morena: "[M]ujé con la cara morena, que é una Virgen der Carmen..." (Expresión del habla gitana de España, en Pastor Petit 1969:407).

No se puede olvidar tampoco que en el mundo andino -como ha asegurado José Limonchi-el color negro o moreno está asociado a lo femenino, a lo primigenio y al amor o a la ayuda solidaria (la expresión "yana", "negro", de donde "yanapanacuni", "ayudarse el uno al otro", o "Yanawara", "estrella amorosa"). "Por su connotación femenina, la coloración negra también está estrechamente vinculada al concepto de ayuda, que alude al lado maternal de la hembra, sentimiento voluntarioso de protección prodigado hacia el hijo o ser amado, $[\ldots]$ " (Limonchi 2007).

La imagen de la 'china' de Andacollo articuló, entonces, una riquísima variedad de arquetipos -andinos, hispanorientales, probablemente africanos- que contribuyeron a los orígenes rituales de la convivialidad amorosa del pueblo mestizo de Chile. Una real vida social que no estuvo determinada por la mitología patriarcal y la cultura mestiza de la 'violación', situación donde lo femenino pasaría a ser reprimido y el destino de la vida culminaría en la desembocadura de la muerte (Esta visión trágica del mestizaje en Palma 1990:13-38). Al contrario, la simbólica de la 'morenita' de Andacollo alentó una cultura exultante de vida, solidaria, igualitaria - los hijos de la 'china' - que causaría alarma a la elite criolla del siglo XIX. Hablando de los mineros, representantes de la cultura popular del norte de Chile y de la 'china' de Andacollo, comentó Domingo Faustino Sarmiento en 1841:

[El] minero es un ser indomable, corrompido por principios y por hábito, no conociendo de la sociedad sino lo que tiene de más degradante e innoble [...] [A] cada momento está dispuesto a sublevarse contra todo obstáculo, seguro de encontrar solícito y cordial apoyo en sus compañeros [...]. Muy diferente de un campamento de soldados, en que la disciplina y la dependencia forzada y absoluta mantienen la moral y el orden, un asiento de minas es una verdadera democracia, [...] (Sarmiento 1973 [1841]: 23-24. Sobre la china de Andacollo, M. Salinas 1994).

El mestizaje del norte de Chile -que tuvo su vigorosa representación ritual en la 'china' de Andacollo-no tardó en expresarse en comportamientos históricos y sociales. En particular, estimamos, alcanzó una representación poética en una mujer heredera del encuentro de la cultura diaguita, la cultura africana y la cultura de Al Ándalus: Lucila Godoy Alcayaga, Gabriela Mistral (1889-1957). "[Por] el lado paterno, en la línea Godoy, estaba presente la sangre de los africanos. Por el mismo 
lado paterno, estaba la familia Huanchicai de sangre indígena. Había también algunas familias españolas como de apellido Villanueva que era originaria de Sevilla" (Papen 1989:23). En este inusitado encuentro de culturas, Gabriela Mistral -con el mismo fervor de la 'china' de Andacollo-representó la forma mestiza de la vida amorosa, que no vino a separar sino a unir las humanidades de América del Sur. Proporcionando vida. Y no muerte. En 1947 le reprochó a Sara Izquierdo Phillips, mujer de la elite 'hispanista' y conservadora de su país: "[Su] España, querida y venerada mía, se puso hace siglos a matar y morir" (Taylor 1975:171). La poetisa de raíz campesina, y con la fluidez de sus ascendientes morenos, apuntaba a la plenitud del amor, a la realización de una cultura y de un lenguaje inequívocamente matrízticos. Así se lo dijeron a su regreso a Chile en 1954:

No habéis nacido ni venido para dividirnos, sino para unirnos en torno al ideal de una América pacífica que respeta a la persona humana [...]. A este mundo americano nuestro le disteis nombres y empezasteis a transformarlo en morada humana, pues sentíais que América era vuestra casa y que debía ser también casa nuestra. ¡Cuánto habéis acercado a nuestros pueblos, [...], hablándonos de esta humanidad tierna y oculta que vive en nuestros grandes espacios! [...] [Vuestra] gran enseñanza está en que nos dijisteis que esa soledad no es nunca extrema, y que aun en la miseria del alma hay esperanza, si la vocación del
Universo no es otra cosa que ese Amor que habéis entrevisto, señora, en los cielos, en suelos fértiles y en áridos terrones, en la tempestad, en el ave que vuela, en árboles, bestezuelas y florecillas, ese amor de que habéis contagiado a tanto corazón humano (Oyarzún 1967:70-76) ${ }^{13}$.

En términos simbólicos y reales, la cultura amorosa de las mujeres morenas de Chile logró ponerse fuera de la representación binaria / jerárquica del sistema patriarcal donde el bien residió en el 'arriba' imaginario de una blancura abnegada (la sublimidad del 'cielo', el mundo de las 'señoras') y el mal en un 'abajo' de una oscuridad viciosa y libertina (el mundo del 'infierno', el universo condenado de las 'rotas'). Las culturas matrízticas de las mujeres indígenas, hispanoárabes o moriscas y africanas, en el conjunto de las mujeres 'morenas', dejaron instalada - por lo menos- la plenitud de una convivencia amorosa universal y terrestre (Sobre el sentido amoroso del mundo en Violeta Parra, Chávez: 2001. Sobre el imaginario patriarcal en América del Sur, Potthast: 2010).

Agradecimientos: Esta investigación fue realizada en el marco del proyecto Fondecyt 1085056 (2008-2010) El amor como vida del mundo en la historia de la cultura y la sensibilidad populares en Chile y América del Sur, siglos XIX y XX, donde el autor fue investigador responsable. El autor agradece el estimulante trabajo de revisión realizado por los evaluadores de este artículo. De este modo se ha enriquecido notablemente.

\section{Referencias Citadas}

Acevedo Hernández, A. 1953. La Cueca. Orígenes, Historia y Antología. Nascimento, Santiago.

Alonqueo, M. 1985. Mapuche Ayer-Hoy. Ediciones Kolping, Padre Las Casas.

Araya, A. 2004. La pureza y la carne: el cuerpo de las mujeres en el imaginario político de la sociedad colonial. Revista de Historia Social y de las Mentalidades VIII:67-90.

_ _ _ 2008. Un imaginario para la mezcla. Mujeres, cuerpo y sociedad colonial. En Mujeres chilenas. Fragmentos de una historia, compilado por S. Montecino, pp. 31-40. Catalonia, Santiago.

Aretz, I. 1978. Música Tradicional de La Rioja. Editora Venegráfica, Caracas.
Arnold, S.G. 1951. Viaje por América del Sur 1847-1848. Emecé, Buenos Aires.

Bayo, C. 1910. Vocabulario Criollo-Español Sud-Americano. Librería de los Sucesores de Hernando, Madrid.

Bendezú, E. 2003. Literatura Quechua. Universidad Ricardo Palma, Lima.

Bengoa, J. 2007. Historia de los Antiguos Mapuches del Sur. Catalonia, Santiago.

Bernand, C. y S. Gruzinski 1999. Historia del Nuevo Mundo. II. Los mestizajes, 1550-1640. FCE, México.

Cáceres Enríquez, J. 1995. La mujer morisca o esclava blanca en el Perú del siglo XVI. Sharq Al-Ándalus 12:565-574. 
Carvallo Goyeneche, V. 1796. Desidia y diversiones de los indios de Chile. En Segunda Parte de la Descripción HistóricoJeográfica del Reino de Chile. Colección de Historiadores de Chile, tomo X.

Casanova, H. 1994. Diablos, Brujos y Espíritus Maléficos. Chillán, un Proceso Judicial del Siglo XVIII. Ediciones Universidad de La Frontera, Temuco.

Castillo, C. 1985-1986. Las huríes en la tradición musulmana. Miscelánea de Estudios Árabes y Hebraicos 34-35:7-18.

Cavieres, E. y R. Salinas 1991. Amor, Sexo y Matrimonio en Chile Tradicional. Ediciones Universitarias, Valparaíso.

Cerda Pincheira, P. 1989. Las mujeres en la sociedad fronteriza del Chile colonial. Jahrbuch für Geschichte von Staat, Wirtschaft und Gesellschaft Lateinamerikas 26:157-171.

Chávez, P. 2001. Ser con otro: el valor de la solidaridad en Violeta Parra. Mapocho. Revista de Humanidades 49:235-248.

D’Orbigny, A.D. 1958. Viaje a la América meridional. En Viajes y viajeros. Viajes por América del Sur. Pp. 15-920. Aguilar, Madrid.

De la Cueva, M. 2004. Las mestizas insolentes y el respeto: la redefinición del mestizaje. En Indígenas Mestizos. Raza y Cultura en el Cusco, editado por M. de la Cadena, pp. 198-250. Instituto de Estudios Peruanos, Lima.

Delgado, C. 1991. El Diálogo de los Mundos. Ensayo sobre el Inca Garcilaso. Universidad Nacional de San Agustín, Arequipa.

Delgado, L. 2000. La africanía en América. En Lo Africano en la Cultura Criolla, editado por M. Rostoworowski, pp. 79-96. Ediciones del Congreso del Perú, Lima.

Denola, J. 1964. La Vida Cotidiana en el Perú en Tiempos de los Españoles 1710-1820. Hachette, Buenos Aires.

Edwards Bello, J. 1955. Valparaíso. Editorial Nascimento, Santiago.

Ellefsen, B. 1989. Matrimonio y Sexo en el Incario. Editorial Los Amigos del Libro, Cochabamba-La Paz.

Esteva Fábregat, C. 1988. El Mestizaje en Iberoamérica. Alhambra, Madrid.

Fourquet-Reed, L. 2004. Humor carnavalesco y erótico en La Lozana andaluza de Francisco Delicado. En Essays on Luso-Hispanic Humor, editado por P.W. Seaver, pp. 53-60. Lewiston, New York.

Flusche, D.M. y E. Korth 1983. Forgotten Females: Women of African and Indian Descent in Colonial Chile, 1535-1800. Blaine Ethridge Books, Detroit.

Galmés de Fuentes, A. 2004. Estudios sobre la Lliteratura Española Aljamiado-Morisca. Fundación Ramón Menéndez Pidal, Madrid.

García, I. 1963 [1745]. Novena de la Virgen de Pastoriza que sale a luz para mayor culto de la Reina de los Angeles, Lima. En Biblioteca Hispano Chilena editado por J.T. Medina, Tomo II. Fondo Histórico y Bibliográfico José Toribio Medina, Santiago.

Garrido, P. 1979. Historial de la Cueca. Ediciones Universitarias, Valparaíso.

Ginobili, M.E. 1996. La cautiva: clave del mestizaje biológico y cultural en la vida fronteriza. En Araucanía y pampas. Un mundo fronterizo en América del Sur, editado por J. Pinto Rodríguez, pp. 134-145. Universidad de La Frontera, Temuco.

Góngora, A. 1994. La Prostitución en Santiago 1813-1931. La Visión de las Elites. Dibam, Santiago.

González, C. 2008. La vida cotidiana de las esclavas negras: espacio doméstico y relaciones familiares en Chile colonial. En Mujeres Chilenas. Fragmentos de una Historia, compilado por S. Montecino, pp. 41-52. Catalonia, Santiago.

Guevara, T. 1908. Psicología del pueblo araucano. Cervantes, Santiago.

Head, F. B. 1920. Las Pampas y los Andes. Notas de viaje. Administración General Vaccaro, Buenos Aires.

Hernández, F. 2002. La Mujer en el Tahuantinsuyo. Universidad Católica del Perú, Lima.

Holguín, O. 2000. Ricardo Palma y la cultura negra. En $L o$ Africano en la Cultura Criolla, editado por M. Rostoworowski, pp. 97-120. Ediciones del Congreso del Perú, Lima.

Kellog, S. 2005. Weaving the Past: A History of Latin America's Indigenous Women from the Prehispanic Period to the Present. Oxford University Press, Oxford.

Lanuza y Sotelo, E. 1998. Viaje Ilustrado a los Reinos del Perú en el Siglo XVIII. Pontificia Universidad Católica del Perú, Lima.

Lavallé, B. 1999. Amor y Opresión en los Andes Coloniales. Instituto de Estudios Peruanos, Lima.

Lehmann-Nitsche, R. 1981. Textos Eróticos del Río de la Plata. Librería Clásica, Buenos Aires.

Leites, E. 1990. La Invención de la Mujer Casta. La Conciencia Puritana y la Sexualidad Moderna. Siglo XXI de España, Madrid.

Lentini, J. 2004. Las formas del deseo. En El Primer Eros. Africa, América, Oceanía, editado por Instituto de Cultura de Barcelona, pp. 39-78. Lunwerg Editores, Barcelona.

Lenz, R. 1905-1910. Diccionario Etimológico de las Voces Chilenas Derivadas de Lenguas Indígenas Americanas. Universidad de Chile, Santiago.

León. L. 2005. Araucanía: la Violencia Mestiza y el Mito de la 'Pacificación', 1880-1900. Arcis, Santiago.

Limonchi, J. 2007. Las danzas de negros en las festividades andinas: origen y exégesis de sus significados. En Africanos y Pueblos Originarios (Relaciones Interculturales en el Área Andina), editado por S. Arteaga y L. Rocca Torres. Museo Afroperuano-UNESCO, Lima.

Mannarelli, M.E. 1998. Hechiceras, Beatas y Expósitas. Mujeres y Poder Inquisitorial en Lima. Ediciones del Congreso del Perú, Lima.

Manquilef, M. 1911. Comentarios del Pueblo Araucano (la Faz Social). Imprenta Cervantes, Santiago.

Maturana, H. 2007. Amor y Juego. Fundamentos Olvidados de lo Humano. José Sáez Editor, Santiago.

- _ _ 2008. El Sentido de lo Humano. José Sáez Editor, Santiago.

Matthei, M. 1983. Visión de Chile a través de una carta de un misionero bávaro en 1742. Anuario de Historia de la Iglesia en Chile, Vol. 1, No $1,209$. 
Mellet, J. 1959. Viajes por el Interior de la América Meridional 1808-1820. Editorial del Pacífico, Santiago.

Mernissi, F. 2003. Las Sultanas Olvidadas de la Historia. La Historia Silenciada de las Reinas del Islam. El Aleph Editores, Barcelona.

_ _ _ 2006. El Majliss, o el placer como ritual sagrado. En El Harén en Occidente, editado por F. Mernissi, pp. 151-166. Espasa Calpe, Madrid.

- _ _ 2007. El Miedo a la Modernidad. Islam y Democracia. Ediciones del Oriente y del Mediterráneo, Madrid.

Mistral, G. 1949. Recado de navidad. Ábside Revista de Cultura Mejicana 13.

- _ _ 1978. Recados para América. Instituto Alejandro Lipschütz, Santiago.

- _ _ 1994 [1946] Sobre la mujer chilena. En Escritos Políticos. Pp. 61-65. Fondo de Cultura Económica, Santiago.

Molina, E. 1917. Ensayo sobre los sudamericanos. En Las Democracias Americanas y sus Deberes, editado por L.S. Rowe y E. Molina, pp. 42-44. Imprenta Universitaria, Santiago.

Montecino, S. 2010 [1985]. Madres y huachos. Alegorías del Mestizaje Chileno. Catalonia, Santiago.

Mörner, M. 1969. La Mezcla de Razas en la Historia de América Latina. Paidós, Buenos Aires.

Moya, I. 1944. Refranero. Imprenta de la Universidad, Buenos Aires.

Mühn, J. 1946. La Argentina vista por Viajeros del Siglo XVIII. Biblioteca Enciclopédica Argentina, Buenos Aires.

Núñez, H. 1997. Poesía Popular y Cuecas. Sociedad Chilena del Derecho de Autor, Santiago.

Olaechea, J.B. 1992. El Mestizaje como Gesta. Mapfre, Madrid. Oyarzún, L. 1967. Dos discursos en honor de Gabriela Mistral. En Temas de la Cultura Chilena, editado por L. Oyarzún, pp. 69-83. Editorial Universitaria, Santiago.

Palma, M. 1990. Malinche. El malinchismo o el lado femenino de la sociedad mestiza. En Simbólica de la Feminidad. La Mujer en el Imaginario Mítico-Religioso de las Sociedades Indias y Mestizas, coordinado por M. Palma, pp. 13-38. Ediciones Abya-Yala, Quito.

Papen, G. 1989. Una Campesina Llamada Lucila de María (Gabriela Mistral y su Origen Familiar). Instituto Nacional de Pastoral Rural, Santiago.

Pastor Petit, D. 1969. 3000 Años de Humor. Ediciones Martínez Roca, Barcelona.

Parra, R. 1999. La negra Ester. En Poesía Popular, Cuecas Choras y La Negra Ester. Pp. 127-202. Fondo de Cultura Económica, Santiago.

Patiño, V. M. 1993. Historia de la Cultura Material en la América Equinoccial. Tomo VII. Vida Erótica y Costumbres Higiénicas. Instituto Caro y Cuervo, Bogotá.

Peña González, P. 2000. La Casa de Corrección de Mujeres: una unidad de producción, en Mujeres ausentes, miradas presentes. IV Jornadas de Investigación en Historia de la Mujer, compilado por P. Peña y P. Zamorano, pp. 109-132. Facultad de Filosofía y Humanidades, Universidad de Chile, Santiago.

Pistone, C. 1992. Indias, mestizas y españolas en la época de la conquista de América. Revista de la Junta Provincial de Estudios Históricos de Santa Fe 58:119-129.

Portocarrero, G. 2007. Racismo y Mestizaje y otros Ensayos. Congreso del Perú, Lima.

Potthast, B. 2010. Mujeres y madres; hombres y machos. Representaciones de feminidad y hombría en América Latina. En Madres, Obreras, Amantes... Protagonismo Femenino en la Historia de América Latina, editado por B. Potthast, pp. 353-363. Iberoamericana / Vervuert, Madrid, Frankfurt.

Rodríguez-Puértolas, J. 1992. Amor, sexualidad y libertad: la mujer en la literatura castellana del siglo XV. En Discurso Erótico y Discurso Transgresor en la Cultura Peninsular, Siglos $X I$ al XX, coordinado por M. Díaz-Diocaretz e I.M. Zavala, pp. 29-55. Tuero. Madrid.

Rostoworowski, M. 1983. Estructuras Andinas del Poder. Ideología Religiosa y Política. Instituto de Estudios Peruanos, Lima.

- _ _ 2003. Doña Francisca Pizarro. Una Ilustre Mestiza 15341598. Instituto de Estudios Peruanos, Lima.

Rubiera Mata, M.J. 1990. Poesía Femenina Hispanoárabe. Castalia, Madrid.

Rudelle-Berteaud, E. 2002. Divergencias moriscas y cristianas sobre erotismo y afectividad. IX Jornadas Interdisciplinarias de Religión y Cultura, pp. 199-207. Universidad de Chile, Santiago,

Salazar, G. 1985. Labradores, Peones y Proletarios. Formación y Crisis de la Sociedad Popular Chilena del Siglo XIX. Sur, Santiago.

. _ _ 1992. La mujer de ‘bajo pueblo’ en Chile: bosquejo histórico. Proposiciones 21:89-107.

Salinas, C. 1994. Las Chilenas de la Colonia. Virtud Sumisa, Amor Rebelde. Lom, Santiago.

Salinas, M. 1992. Christianity, Colonialism and Women in Latin America in the 16th, 17th and 18th Centuries, Social Compass. International Review of Sociology of Religion 39:525-542.

- - - 1994. Andacollo. En Lexikon für Theologie und Kirche. Herder Verlag, Freiburg, Band 1, col. 616.

_ _ _ 2011. El amor en la poesía y el canto popular de Chile. Un manuscrito inédito de Rodolfo Lenz: Die echte Volkspoesie. Dichtung und Musik der Frauen (1894). En Ideas Viajeras y sus Objetos: El Intercambio Científico entre Alemania y América Austral, editado por G. Chicote y B. Göbel, pp. 305-319. Iberoamericana / Vervuert, Berlín.

Santa Cruz, N. 1982. La Décima en el Perú. Instituto de Estudios Peruanos, Lima.

Salvador Martínez, H. 2006. La Convivencia en la España del Siglo XIII. Perspectivas Alfonsíes. Ediciones Polifemo, Madrid.

Sarmiento, D.F. 1973 [1841]. Los mineros. En Chile. Descripciones, Viajes, Episodios, Costumbres. Eudeba, Buenos Aires.

Satz, M. 2005. El Cantar de los Cantares o los Aromas del Amor. Kairós, Barcelona. 
Schmidt, P. 1997. Neoestoicismo y disciplinamiento social en Iberoamérica Colonial (siglo XVII). En Pensamiento Europeo y Cultura Colonial, editado por K. Kohut y S. Rose, pp. 181-204. Vervuert / Iberoamericana, Frankfurt, Madrid.

Sínodos de Santiago de Chile 1688 y 1763 1983. En Sínodos Americanos 2, Serie dirigida por A. García y García y H. SantiagoOtero. Instituto Francisco Suárez del Consejo Superior de Investigaciones Científicas, Madrid-Salamanca.

Sosa, P. de 1963 [1616]. Memorial del peligroso estado espiritual y temporal del reino de Chile. En Biblioteca Hispano Chilena, editado por J.T. Medina, Tomo II, pp. 158-193. Fondo José Toribio Medina, Santiago.

Soto, R. 1992. Negras esclavas. Las otras mujeres de la Colonia. Proposiciones 21:36-49.

Subercaseaux, B. 1954. Dos Chiles. Zig-Zag, Santiago.

Taylor, M. 1975. Sensibilidad Religiosa de Gabriela Mistral. Gredos, Madrid.

Triviños, G. 1994. La Polilla de la Guerra en el Reino de Chile. Editorial La Noria, Santiago.
Uribe Echevarría, J. 1974. La Virgen de Andacollo y el Niño Dios de Sotaquí. Ediciones Universitarias de Valparaíso, Santiago.

Vargas, L. 1995. Vuestra Gabriela. Zig-Zag, Santiago.

Vasconcelos, J. 1946. Homenaje a Gabriela Mistral. Revista Iberoamericana X 20:224.

Vassallo, J. 2006. Delincuentes y pecadoras en la Córdoba tardo colonial. Anuario de Estudios Americanos 63:97-116.

Wade, P. 2005. Rethinking mestizaje: Ideology and lived experience. Journal of Latin American Studies 37:239-257.

Zaramaira 2007. El Poder y la Dulzura de Oshun en Sintonía con los Orishas. Colección Todo Santería. Editorial Panapo, Caracas.

Zúñiga, J.-P. 2000. Morena me llaman... Exclusión e integración de los afroamericanos en Hispanoamérica: el ejemplo de algunas regiones del antiguo virreinato del Perú (siglos XVI-XVIII). En Negros, Mulatos, Zambaigos. Derroteros Africanos en los Mundos Ibéricos, coordinado por B. Ares y A. Stella, pp. 105-122. Consejo Superior de Investigaciones Científicas, Sevilla.

\section{Notas}

1 Felipe Guamán Puma de Ayala en el siglo XVII expresó que los mestizos eran una "raza maldita" que había que exiliar a Chile (Bernand y Gruzinski 1999:101).

2 "Santiago de Chile en el siglo XVII estaba marcado, como la mayoría de las ciudades coloniales, por una fuerte impronta africana" (Zúñiga 2000:116-117).

3 Las formas de negación del amor en el mundo andino colonial (Lavallé 1999).

4 "Las mujeres, [...], tuvieron un contacto más directo y estrecho con los conquistadores, por ser amantes, esposas, mancebas, prostitutas o sirvientas; [...] Ellas compartían la vida diaria de los hispanos, cohabitaban con ellos según sus diferentes condiciones" (Rostoworowski 2003:15).

5 En el Perú "china" se asocia con zamba o mulata. "Según el tipo de mestizaje se dice "chinachola", "china-prieta", "china-clara", etc. (Santa Cruz 1982:309).

6 Los misioneros católicos de la época española temieron la condición amorosa de las mujeres indígenas de América. Uno de ellos dijo de las mujeres guajiras en el siglo XVIII: "De toda la observación que hice de los ritos y políticas de estos gentiles, hallé por más peligrosas los cariños y ternuras a que son dadas las mujeres de esta nación. Asalto el mayor que debe temer la honestidad es la blandura de una mujer" (Patiño 1993:128). El cronista Cieza de León caracterizó a las mujeres andinas como "no poco ardientes de lujuria" (Esteva Fábregat 1988:130). Ulrich Schmidel comentó de las mujeres indígenas jarabes: "Muy lindas y grandes amantes y afectuosas y son ardientes de cuerpo, según mi parecer" (Mörner 1969:32).

7 De acuerdo a las tradiciones musulmanas cada bienaventurado en el Paraíso se casaría con cuatro mil vírgenes, ocho mil viudas y cien huríes, Castillo 1985-1986.

8 "Andando en todo tiempo ligeras y desembarazadas, con poca ropa, casi en camisa,..." (Galmés de Fuentes 2004:20).

9 El cancionero popular de Chile representa esta imagen de la mujer afrodescendiente: "Una zamba me miraba / y con el ojo me hacía... / ¡Güeno con la zamba diabla / too lo que me decía...! / Las zambas son muy lindas, / muy mordeoras, / gritan si las aprietan / riéndose solas. / Riéndose solas, sí, / zambita suave, / no le contís a nadie / lo que se sabe. / No hay con ellas quien tope, / zambas de arrope" (Acevedo Hernández 1953:340-341). En Perú Ricardo Palma describió con estos términos a Gertrudis, una joven esclava: "Fresca como un sorbete, traviesa como un duende, alegre como una misa de aguinaldo y con un par de ojos negros, tan negros, que parecían hechos de tinieblas [...], no había en Lima más diestra tañedora de arpa, ni timbre de voz más puro y flexible para cantar la 'bella Aminta' y el 'pastor feliz', ni pies más ágiles para trenzar una 'sajuriana', ni cintura más cenceña y revolucionaria para bailar un bailecito de la tierra" (Holguín 2000:115).

10 "Soy la reina de lah playah / por esto nadie se asombre / me gustan todoh loh hombreh / son ricoh de todah layah / pa jugar a la payaya / loh porteñoh y marinoh / me gustan loh santiaguinoh / carrilanoh y mineroh / un abrazo al mundo entero / brindemoh con el gran vino. / En el puerto estoy de rosa / aquí yo no siento pena / se acabaron lah cadenah / a volar la mariposa / soy ardiente y cariñosa / quiero a Pedro, Juan y Diego / voy a decir hasta luego / esto ya no tiene nombre / mi cuerpo es pa'loh hombreh / con esto a nadie ruego" (Parra 1999:143-144).

11 "[La] identificación con la imagen idealizada del padre blanco, [...] condena al mestizo a la 'hybris', a la repetición en el presente de la violencia, del acto real (histórico) de la conquista" (Delgado 1991:334).

12 Los curas no debían traer a sus casas "con ningún pretexto, Chinas muchachas", prescribió el sínodo diocesano de Santiago de Chile de 1688 (Sínodos de Santiago de Chile 1688 y $17631983: 34)$.

13 Gabriela Mistral fundó el mundo de la vida desde el amor: "Aquello mismo que nos rodeaba no había sido conocido 
porque no era amado y sólo esa quemante pasión amorosa que es la poesía fue capaz de descubrir, junto con su existencia, su virtud. Estas almas de poder visionario fundan el mundo [...]. Sin esa poesía, la tierra sería inhóspita como un astro muerto y nada de lo humano puede desplegarse [...]. A cierta profundidad de la vida, el corazón humano olvida sus límites y sus resentimientos y tiembla sólo para expresar, en la transparencia del lenguaje, aquello que es tan esencial a la existencia como el aire: el amor descubridor del mundo, el que exalta y consuela, el amor que perdona, el que, transformado en ojos, ve y vuela hasta las últimas distancias" (Oyarzún 1967:78-79). 